\title{
LOCOMOTOR PERFORMANCE AND ENERGETIC COST OF SIDEWINDING BY THE SNAKE CROTALUS CERASTES
}

\author{
BY STEPHEN M. SECOR,
}

Department of Biology, University of California, Los Angeles, CA 90024, USA BRUCE C. JAYNE

Department of Biological Sciences, ML6, University of Cincinnati, OH 45221-0006, USA

AND ALBERT F. BENNETT

Department of Ecology and Evolutionary Biology, University of California, Irvine, CA 92717, USA

\section{Accepted 27 June 1991}

\begin{abstract}
Summary
We measured the performance (burst speed and endurance) and the energetic cost of sidewinding locomotion for the viperid snake Crotalus cerastes. The linear scaling regressions relating log mass to log burst speed and log endurance have slopes of 0.29 and 1.01, respectively. Maximal burst speed observed for an individual snake ( $S V L=41.9 \mathrm{~cm}, S V L$ is snout-vent length) was $3.7 \mathrm{~km} \mathrm{~h}^{-1}$. Adult snakes were able to match a tread speed of $0.5 \mathrm{~km} \mathrm{~h}^{-1}$ for times ranging from 33 to more than $180 \mathrm{~min}$, and at $0.7 \mathrm{~km} \mathrm{~h}^{-1}$ endurance times ranged from 9 to $52 \mathrm{~min}$. Rates of oxygen consumption increased linearly over a range of aerobically sustainable speeds $\left(0.28-0.50 \mathrm{~km} \mathrm{~h}^{-1}\right)$, with a resulting net cost of transport (NCT) of $0.408 \mathrm{ml} \mathrm{O}_{2} \mathrm{~g}^{-1} \mathrm{~km}^{-1}$ for eight snakes with a mean mass of $110 \mathrm{~g}$. Sidewinding of $C$. cerastes involves periodic movements with a frequency that increases linearly with mean forward speed. At $0.50 \mathrm{~km} \mathrm{~h}^{-1}$, the mean $(N=8)$ mass-specific energetic cost per cycle of movement was $0.28 \mu \mathrm{O} \mathrm{O}_{2} \mathrm{~g}^{-1}$ cycle $^{-1}$ for sidewinding. The NCT and the cost per cycle of movement of $C$. cerastes sidewinding are significantly less than those of similar mass snakes (Coluber constrictor) performing either terrestrial lateral undulation or concertina locomotion. The NCT of $C$. cerastes sidewinding is also significantly less than that predicted for the terrestrial limbed locomotion of lizards of similar mass. Mean $\dot{V}_{\mathrm{O}_{2} \max }$ of $C$. cerastes $\left(0.405 \mathrm{ml} \mathrm{O}_{2} \mathrm{~g}^{-1} \mathrm{~h}^{-1}\right)$ is only about half that reported for $C$. constrictor; however, the mean endurance at $0.60 \mathrm{~km} \mathrm{~h}^{-1}(73 \mathrm{~min})$ for sidewinding $C$. cerastes does not differ significantly from that reported for $C$. constrictor laterally undulating.
\end{abstract}

\section{Introduction}

The loss of limbs has evolved independently within several major groups of Key words: burst speed, endurance, oxygen consumption, cost of transport, Crotalus cerastes. 
vertebrates (Gans, 1974; Edwards, 1985). The best known and most diverse of these lineages is the snakes, a monophyletic group (Cadle, 1987) containing more than 2000 species (Duellman, 1979). Snakes may use different locomotor behaviours depending upon speed and the topography of the locomotor surface (Gray, 1946; Gans, 1974; Jayne, 1986). One mode of limbless locomotion, apparently unique to snakes, is sidewinding (Gans, 1974). Sidewinding is the primary locomotor behaviour of some specialized species in their natural environment, yet many other species of snake will sidewind when they encounter smooth surfaces such as sand or mud (Gans, 1974; Jayne, 1986).

In contrast to the lateral undulatory and concertina modes of limbless locomotion, during sidewinding there is no sliding contact with the substratum (Mosauer, 1932; Gray, 1946; Gans, 1974; Jayne, 1986). A sidewinding snake simultaneously bends and lifts its body while maintaining two regions of static contact between its belly and the ground. The resulting pattern of movement leaves a series of disconnected tracks that are oblique relative to the overall direction of travel (Mosauer, 1935; see Fig. 1). Although these general aspects of kinematics are well documented, no study of sidewinding has systematically determined speed, endurance or the scaling of these measures of locomotor performance.

For diverse groups of limbed animals, the energetic cost of locomotion appears to be determined primarily by the mass of the animal (Bennett, 1985; Full, 1989). For snakes, the choice of locomotor mode significantly affects locomotor energetics. For example, the energetic cost of concertina locomotion is seven times greater than that of lateral undulation (Walton et al. 1990). Furthermore, this variation in energetic cost between modes of limbless locomotion is large compared to that of the net cost of transport of limbed lizards of similar mass (John-Alder et al. 1986). The objectives of this study examining sidewinding locomotion are (1) to determine the scaling of burst speed and endurance with size, (2) to determine the energetic cost of this mode and (3) to compare these values with those for different modes of limbless locomotion.

\section{Materials and methods}

The sidewinder (Crotalus cerastes Hallowell) is a small species of rattlesnake which chiefly inhabits the sandier regions of the Sonoran and Mojave Deserts of North America (Klauber, 1972). This snake employs sidewinding as its primary locomotory mode (Mosauer, 1932; Klauber, 1972). Snakes used in this study were captured in San Bernardino Co., California, USA (CA Dept. Fish and Game permit no. 0690 to B.C.J.). After experiments, snakes were measured [snout-vent length $(S V L)$ and total length $(T L)$ to the nearest millimetre], weighed (to the nearest gram) and sexed (Fitch, 1987). Locomotor performance was measured for 41 snakes $(20<S V L<55 \mathrm{~cm} ; 7<$ mass $<147 \mathrm{~g})$, ranging from newborn ( $<1$ month) to adult ( $>4$ years). A subset of eight adult snakes (mean $S V L=51.0 \mathrm{~cm}$, range 
$45.3-54.8 \mathrm{~cm}$; mean $T L=55.1 \mathrm{~cm}$, range $49.5-58.4 \mathrm{~cm}$; mean mass $=110 \mathrm{~g}$, range $79-147 \mathrm{~g}$ ) was used to determine the energetic cost of sidewinding.

Adult and subadult snakes were fed newborn rats every third week and all snakes had access to water ad libitum. Captive sidewinders were housed individually in either small aquaria (19l) or plastic shoe boxes with a $12 \mathrm{~h}$ light: $12 \mathrm{~h}$ dark photoperiod, daytime photothermal gradient of $20-32^{\circ} \mathrm{C}$ and night-time temperatures of approximately $20^{\circ} \mathrm{C}$. All trials were conducted in a temperaturecontrolled room maintained at $30 \pm 1{ }^{\circ} \mathrm{C}$. This temperature is within the range of body temperatures of surface-active $C$. cerastes (Moore, 1978). Prior to the performance and cost trials, paint marks were placed at three positions along the mid-dorsal line of the snake to facilitate kinematic measurements.

\section{Performance testing}

\section{Burst speed}

Burst speed trials were conducted on a 3-m long track, with a floor of smooth, dense rubber matting. Preliminary experiments revealed that this surface minimized slippage by snakes which could impair rapid locomotion. The vertical sides of the track ( $30 \mathrm{~cm}$ high) were adjusted to a width approximating the $S V L$ of the individual being tested. A camera, suspended directly over the track, video-taped ( 60 fields $\mathrm{s}^{-1}$ ) each trial with a shutter speed of $0.001 \mathrm{~s}$ and a time display to the nearest $0.01 \mathrm{~s}$ was recorded on each video field. Two trials (12 days apart) were conducted for each snake. By tapping the mat or the snake's tail with a soft brush, each individual was encouraged to move down the track 3-5 times in rapid succession for each trial. Other studies have recognized the varying behavioural responses of individual snakes to performance testing (Arnold and Bennett, 1984). In our original sample, three sidewinders assumed a defensive posture, refused to crawl and could not be tested.

The motion of sidewinding involves periodic static contact between the snake and the ground. We determined the duration of each cycle of movement $( \pm 0.01 \mathrm{~s})$ over the middle $1.5 \mathrm{~m}$ of the track for each replicate. For the single cycle that was completed in the shortest time, we measured the distance travelled over that time interval (Fig. 1) by using a customized computer program for digitizing data from individual video images. Burst speed was calculated by dividing this distance by the duration of that cycle.

\section{Endurance}

Endurance trials were performed on a motorized treadmill with a tread surface of rubber-impregnated cloth, $100 \mathrm{~cm}$ long and $45 \mathrm{~cm}$ wide. For each of the 41 snakes, a single test of endurance was made using a tread speed of $0.50 \mathrm{~km} \mathrm{~h}^{-1}$. The endurance of six adult snakes (four of which were used to determine energetic cost) was also measured at speeds of $0.60,0.70$ and $0.80 \mathrm{~km} \mathrm{~h}^{-1}$. Snakes were encouraged to keep pace with the treadmill by tapping either the treadmill's surface or the snake's tail. A trial was terminated when an individual failed to 


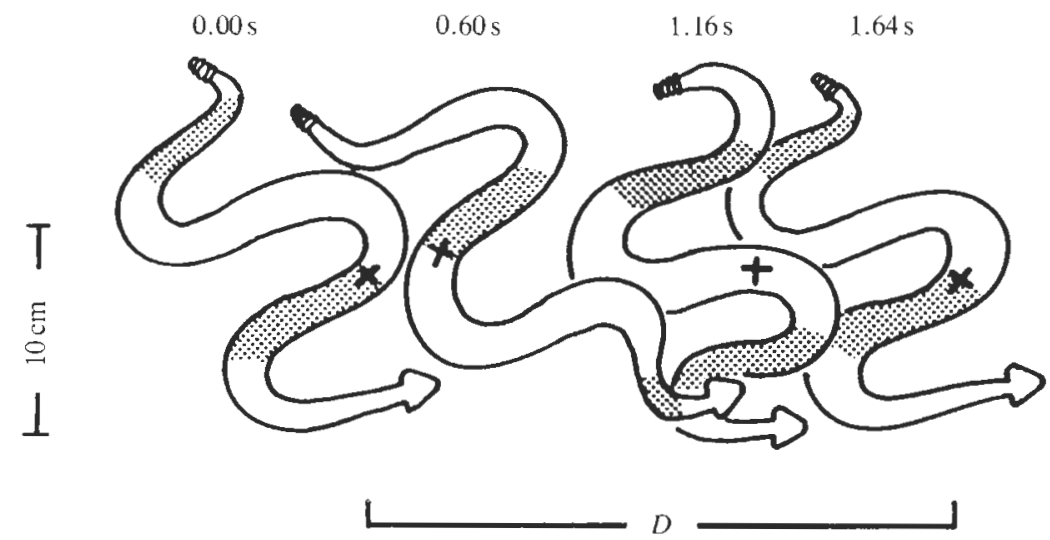

Fig. 1. Diagram drawn from video images of a Crotalus cerastes $(S V L=45.3 \mathrm{~cm})$ sidewinding with $\bar{V}_{\mathrm{x}}$ of $0.60 \mathrm{~km} \mathrm{~h}^{-1}$ illustrating the method used to measure the distance travelled during one cycle of movement $(D)$. One cycle of movement occurs between two successive initiations of static contact with the substratum for a point on the snake's body marked by paint $(+)$.

match tread speed three times in rapid succession. If an individual maintained locomotion for $180 \mathrm{~min}$, the trial was terminated. The endurance for an individual was measured as the time $( \pm 0.5 \mathrm{~min})$ from the beginning of its movement on the treadmill until the end of its trial.

\section{Energetics}

To measure rates of oxygen consumption, a light-weight $(1.9 \mathrm{~g})$ clear plastic mask $(0.8 \mathrm{~mm}$ thick Lexan) enclosed the entire head of the snake and was kept in place with a piece of foam dorsal to the snake's braincase. The mask was designed not to interfere with respiration or sight, or to compress the enlarged supraocular scales. The back of the mask was open and the tapering front of the mask was attached to tubing connected to an oxygen analyzer. Air was drawn $\left(225 \mathrm{ml} \mathrm{min}^{-1}\right)$ through the air line into columns of water absorbent (Drierite) and $\mathrm{CO}_{2}$ absorbent (Ascarite) prior to entering the oxygen analyzer (Applied Electrochemistry, model S-3A). Oxygen content $\left(\% \mathrm{O}_{2}\right)$ of the drawn air was recorded on a chart recorder.

We used tread speeds of $0.28,0.35,0.43,0.50,0.58,0.65$ and $0.73 \mathrm{~km} \mathrm{~h}^{-1}$ to measure oxygen consumption and we video-taped each trial. From playback of the video tapes, we determined the frequency of movement and subjectively rated the quality of the trial. We selected time intervals for calculating average oxygen consumption based upon the consistency and quality of movement (matching tread speed, using the entire body to sidewind, and not climbing treadmill walls). Within each record of oxygen consumption, lasting for 6-15 min for each tread speed, average rates of steady-state oxygen consumption were calculated from points at every $2-s$ interval for the highest quality $2-3$ min span. The average coefficient of variation for 30 -s means of oxygen consumption within each of the 39 
trials was $20 \%$, and only one of these trials had a significant correlation between the 30 -s means and time. Pre-exercise rates of oxygen consumption were measured from masked snakes resting on the treadmill prior to their locomotor trials. All rates of oxygen consumption were corrected for standard pressure and temperature and calculated following the method of Withers (1977) for open-flow mask respirometry.

\section{Statistical analysis}

Most statistical analyses were performed using a microcomputer version of SPSS (PC+ SPSS). Statistical significance was designated at $P<0.05$. Burst speed values, endurance times and size variables of the snakes were log-transformed (base 10) prior to regression analysis of scaling. All regressions were calculated using the least-squares method.

\section{Results \\ Scaling relationships}

Size

Both $T L$ and mass increased with increasing $S V L$ for $C$. cerastes (Table 1). Male and female sidewinders differed in both $T L(\log T L=1.007 \log S V L-0.013 \mathrm{sex}+$ $\left.0.027, r^{2}=0.999\right)$ and mass $\left(\log\right.$ mass $\left.=2.761 \log S V L-0.021 \mathrm{sex}-2.700, r^{2}=0.961\right)$ as indicated by the highly significant $(P<0.001)$ coefficient of a coded variable for sex $(0=$ male, $1=$ female $)$. Hence, for a given $S V L$, these males have longer tails and are heavier than females. Despite its significance, sex of the snake had only small effects on $T L$ and mass, as suggested by similar coefficients of determination $\left(r^{2}\right)$ for the regressions including sex and those using $S V L$ alone (Table 1).

Table 1. Regression equations $\left(\mathrm{y}=\mathrm{a}_{1} \mathrm{x}+\mathrm{a}_{0}\right)$ for the scaling of size and locomotor performance for Crotalus cerastes

\begin{tabular}{|c|c|c|c|c|c|}
\hline$y$ & $a_{1}$ & S.E. & $a_{0}$ & $r^{2}$ & $P$ \\
\hline \multicolumn{6}{|l|}{ Size scaling } \\
\hline $\log T L v s \log S V L$ & 1.007 & \pm 0.009 & 0.022 & 0.997 & $<0.0001$ \\
\hline $\log M v s \log S V L$ & 2.761 & \pm 0.090 & -2.709 & 0.960 & $<0.0001$ \\
\hline \multicolumn{6}{|l|}{ Burst speed scaling } \\
\hline $\log \bar{V}_{\mathrm{x}} v s \log S V L$ & 0.812 & \pm 0.197 & -1.010 & 0.304 & 0.0002 \\
\hline $\log \bar{V}_{\mathrm{x}} v s \log M$ & 0.292 & \pm 0.069 & -0.209 & 0.312 & 0.0001 \\
\hline $\log D$ vs $\log S V L$ & 1.026 & \pm 0.083 & -0.215 & 0.795 & $<0.0001$ \\
\hline $\log f v s \log S V L$ & -0.206 & \pm 0.159 & 0.636 & 0.041 & 0.202 \\
\hline \multicolumn{6}{|l|}{ Endurance scaling } \\
\hline $\log E v s \log S V L$ & 2.852 & \pm 0.425 & -3.095 & 0.536 & $<0.0001$ \\
\hline $\log E v s \log M$ & 1.007 & \pm 0.152 & -0.253 & 0.530 & $<0.0001$ \\
\hline $\begin{array}{l}\text { S.E. is the standard } \\
\text { efficient of determina } \\
\text { See list of abbreviatio }\end{array}$ & $\begin{array}{l}\text { f the slo } \\
\text { f the reg } \\
\text { definitic }\end{array}$ & $\begin{array}{l}\mathrm{V}=41 ; a_{0} \\
\text { on. } \\
\text { variable }\end{array}$ & inter & 1 , is & pe, $r^{2}$ is \\
\hline
\end{tabular}




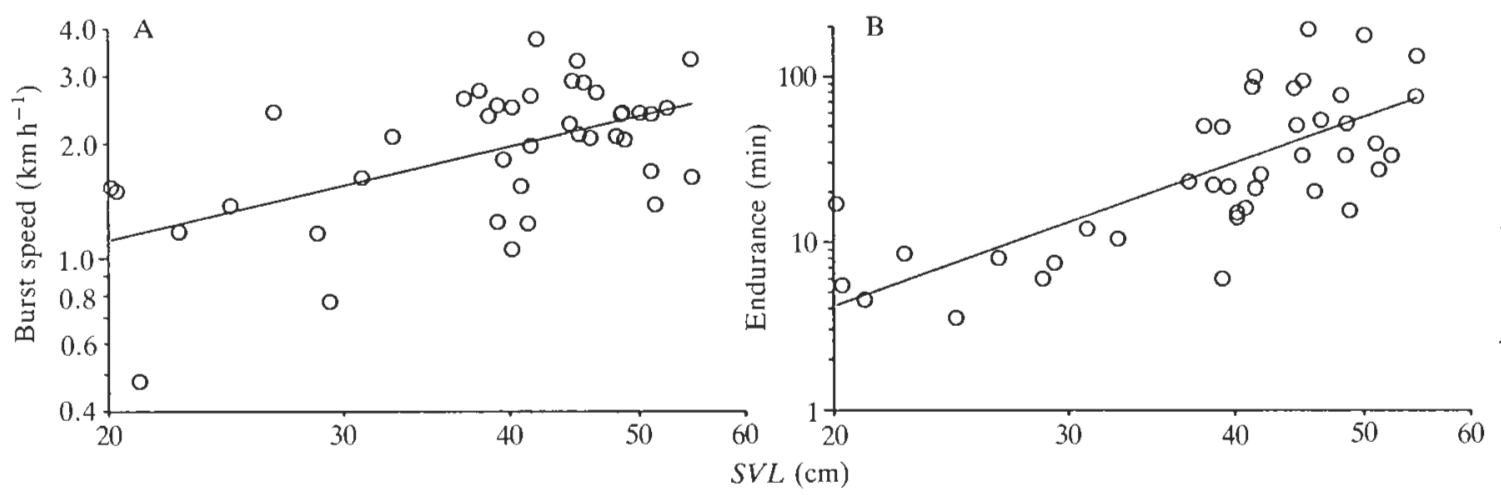

Fig. 2. Log-log plot of performance versus snout-vent length (SVL) for 41 Crotalus cerastes performing sidewinding locomotion. Least-squares linear regressions (Table 1) are shown for each figure. (A) Burst speed. (B) Endurance time at $0.50 \mathrm{~km} \mathrm{~h}^{-1}$.

\section{Burst speed.}

Burst speed of $C$. cerastes ranged from 0.5 to $3.7 \mathrm{~km} \mathrm{~h}^{-1}$ and increased as $S V L$ and mass increased (Table 1). Fig. 2A illustrates the linear increase of log burst speed $\left(\mathrm{km} \mathrm{h}^{-1}\right)$ with increased $\log S V L$, and a multiple regression indicated no significant quadratic effect of $S V L$. The increase in burst speed with $S V L$ resulted primarily from a significant increase in the distance covered per cycle with increased $S V L$, as the maximum frequency of movement during burst speed did not change significantly with $S V L$ (Table 1). A multiple regression revealed that sex had no significant effect on burst speed.

\section{Endurance}

Endurance time at $0.50 \mathrm{~km} \mathrm{~h}^{-1}$ ranged from 3.5 to more than $180 \mathrm{~min}$ and showed a simple linear increase with both $S V L$ and mass (Table 1; Fig. 2B). Males had significantly greater endurance $(E)$ than females $(\log E=2.853 \log S V L-$ 0.228 sex $-2.996, r^{2}=0.594 ; P$ for coefficient of sex $\left.=0.024\right)$.

For a subset of six C. cerastes of similar size, Fig. $3 \mathrm{~A}$ illustrates the decrease of endurance with speed. The mean \pm 1 s.D. endurance times $(\mathrm{min})$ at $0.50,0.60,0.70$ and $0.80 \mathrm{~km} \mathrm{~h}^{-1}$ are $88.4 \pm 58.2,72.9 \pm 61.8,25.5 \pm 19.4$ and $6.3 \pm 5.3$, respectively. Compared to $0.50 \mathrm{~km} \mathrm{~h}^{-1}$, C. cerastes moving at $0.80 \mathrm{~km} \mathrm{~h}^{-1}$ experienced a $93 \%$ reduction in endurance. Despite the initial decline in endurance, there was no significant difference in endurance between 0.50 and $0.60 \mathrm{~km} \mathrm{~h}^{-1}$ (paired $t=0.806)$. At $0.70 \mathrm{~km} \mathrm{~h}^{-1}$, endurance had decreased significantly from that at $0.50 \mathrm{~km} \mathrm{~h}^{-1}$ (paired $t=3.171, P<0.05$ ). Endurance time was highly variable at these speeds, evident from an adult $(S V L=45.3 \mathrm{~cm}$, mass $=79 \mathrm{~g})$ moving continuously for $481 \mathrm{~min}$ at $0.60 \mathrm{~km} \mathrm{~h}^{-1}$ during a preliminary trial. Crotalus cerastes increases speed between 0.30 and $0.80 \mathrm{~km} \mathrm{~h}^{-1}$ by linearly increasing the frequency of sidewinding (Fig. 3B), not the distance per cycle. The frequency of movement (cycles $\mathrm{min}^{-1}$ ) at $0.80 \mathrm{~km} \mathrm{~h}^{-1}$ is nearly 2.5 -times that at $0.30 \mathrm{~km} \mathrm{~h}^{-1}$. 


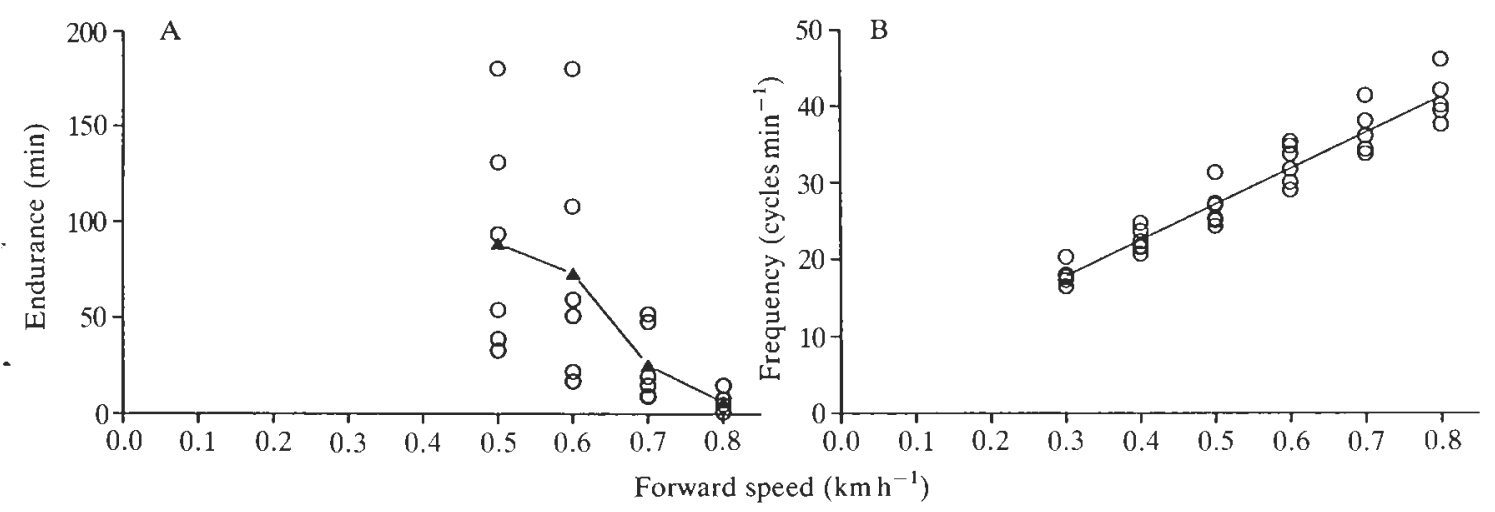

Fig. 3. (A) Endurance and (B) frequency of movement as a function of tread speed for six Crotalus cerastes (mean $S V L=49.2 \mathrm{~cm}$, mean mass $=104 \mathrm{~g}$ ) sidewinding. The leastsquares regression for frequency of movement is: $f\left(\right.$ cycles $\left.\min ^{-1}\right)=46.55( \pm 2.23) \bar{V}_{\mathrm{x}}$ $\left(\mathrm{km} \mathrm{h}^{-1}\right)+3.87\left(r^{2}=0.928, P<0.0001\right) . \boldsymbol{\Delta}$, mean endurance.

\section{Energetics}

For each of the eight $C$. cerastes, rates of oxygen consumption $\left(\mathrm{mlO}_{2} \mathrm{~g}^{-1} \mathrm{~h}^{-1}\right)$ were measured for each of its four slowest speeds (Fig. 4A). Rates of oxygen consumption $\left(\dot{V}_{\mathrm{O}_{2}}\right)$ increased linearly with speed between 0.28 and $0.50 \mathrm{~km} \mathrm{~h}^{-1}$, and maximum $\dot{V}_{\mathrm{O}_{2}}$ was attained between 0.50 and $0.65 \mathrm{~km} \mathrm{~h}^{-1}$ (Fig. $4 \mathrm{~A}$ ). Based on the greatest value of $\dot{V}_{\mathrm{O}_{2}}$ observed for each of the individuals during sidewinding, mean $\dot{V}_{\mathrm{O}_{2} \max }$ was $0.405 \mathrm{ml} \mathrm{O}_{2} \mathrm{~g}^{-1} \mathrm{~h}^{-1}(N=8$, s.E. $=0.026)$. As in previous studies, we related $\dot{V}_{\mathrm{O}_{2}}$ to speed with a regression using all 32 data points from 0.28 to $0.50 \mathrm{~km} \mathrm{~h}^{-1}$. The slope of this regression $(N=32)$, the net cost of transport, was
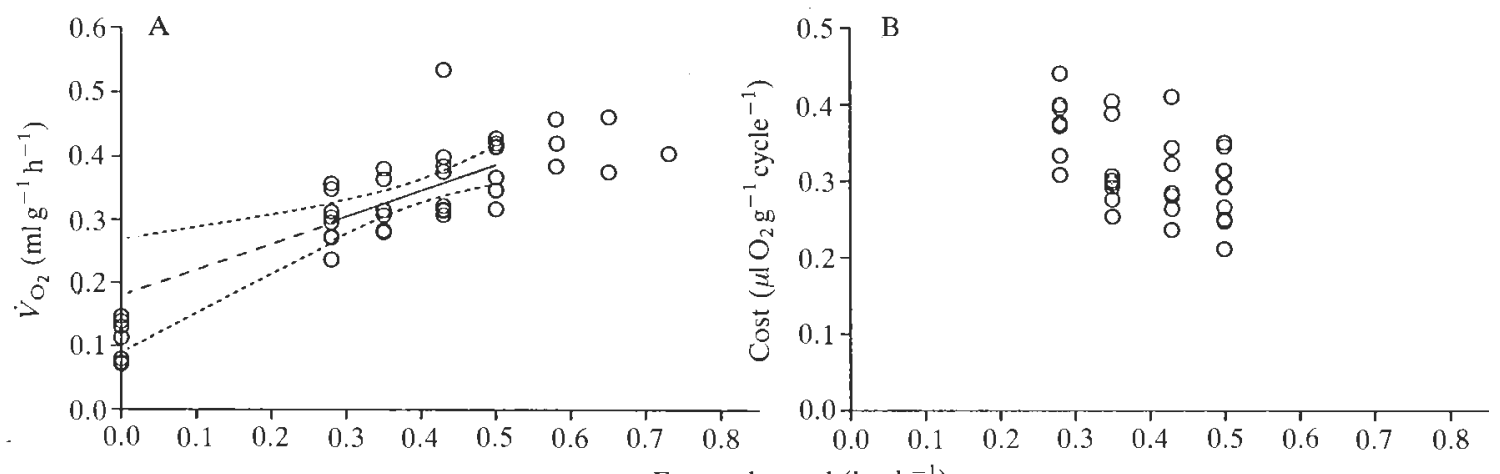

Forward speed $\left(\mathrm{km} \mathrm{h}^{-1}\right)$

Fig. 4. (A) Rates of oxygen consumption $\left(\dot{V}_{\mathrm{O}_{2}}\right)$ versus speed for eight Crotalus cerastes performing sidewinding locomotion. The regression for the increase in $\dot{V}_{\mathrm{O}_{2}}$ for aerobically sustainable speeds $\left(0.28-0.50 \mathrm{~km} \mathrm{~h}^{-1}\right)$ is $\dot{V}_{\mathrm{O}_{2}}=0.408 \bar{V}_{\mathrm{x}}\left(\mathrm{km} \mathrm{h}^{-1}\right)+0.182$ $\left(N=32, r^{2}=0.322, P<0.001\right)$. The dashed lines represent $95 \%$ confidence limits of the regression. Values at $\bar{V}_{\mathrm{x}}=0$ are the pre-exercise $\dot{V}_{\mathrm{O}_{2}}$ values for these snakes. (B) Cost per single cycle of of aerobically sustainable sidewinding by $C$. cerastes versus speed. 
Table 2. Statistics for the regression equations $\left[\dot{V}_{O_{2}}\left(m l O_{2} g^{-1} h^{-1}\right)=\mathrm{a}_{1} \times\right.$ speed $\left(k m h^{-1}\right)+\mathrm{a}_{0}$ J for Crotalus cerastes sidewinding at four aerobically sustainable speeds from 0.28 to $0.50 \mathrm{~km} \mathrm{~h}^{-1}$

\begin{tabular}{lccccccc}
\hline $\begin{array}{l}S V L \\
(\mathrm{~cm})\end{array}$ & $\begin{array}{c}\text { Mass } \\
(\mathrm{g})\end{array}$ & Sex & $a_{1}$ & S.E. & $a_{0}$ & $r^{2}$ & $P$ \\
\hline 45.3 & 79 & M & 0.503 & \pm 0.104 & 0.158 & 0.921 & 0.040 \\
48.1 & 89 & M & 0.576 & \pm 0.580 & 0.182 & 0.330 & 0.425 \\
50.1 & 100 & M & 0.294 & \pm 0.179 & 0.199 & 0.574 & 0.242 \\
51.1 & 104 & F & 0.495 & \pm 0.030 & 0.102 & 0.993 & 0.004 \\
51.1 & 120 & M & 0.561 & \pm 0.094 & 0.149 & 0.947 & 0.027 \\
52.5 & 147 & M & 0.349 & \pm 0.047 & 0.170 & 0.966 & 0.017 \\
54.7 & 119 & F & 0.194 & \pm 0.076 & 0.226 & 0.765 & 0.126 \\
54.8 & 120 & F & 0.289 & \pm 0.041 & 0.272 & 0.962 & 0.019 \\
Mean & & & & & & &
\end{tabular}

Note that the slope $\left(a_{1}\right)$ equals the net cost of transport $(N C T)$.

See list of abbreviations for definitions of variables.

$0.408 \mathrm{ml} \mathrm{O}_{2} \mathrm{~g}^{-1} \mathrm{~km}^{-1}$. Table 2 illustrates an alternative approach involving separate regressions for each individual in order to account for the lack of independence in the observations of oxygen consumption. The slopes of these separate regressions ranged from 0.194 to $0.576 \mathrm{ml} \mathrm{O}_{2} \mathrm{~g}^{-1} \mathrm{~km}^{-1}$ and the mean of these separate slopes was identical to that of the regression utilizing all 32 values. The $y$-intercept of the regression shown in Fig. $4 \mathrm{~A}$ is $0.182 \mathrm{ml} \mathrm{O}_{2} \mathrm{~g}^{-1} \mathrm{~h}^{-1}$, which is significantly greater than zero $(t=4.237, P<0.001)$ and significantly greater than the mean pre-exercise $\dot{V}_{\mathrm{O}_{2}}$ of $0.108 \mathrm{ml} \mathrm{O}_{2} \mathrm{~g}^{-1} \mathrm{~h}^{-1}(t=3.519, P<0.01)$.

The energetic cost per cycle of sidewinding for the four aerobically sustainable speeds is illustrated in Fig. 4B. These values were calculated by dividing massspecific $\dot{V}_{\mathrm{O}_{2}}$ for each individual at a particular speed by the number of cycles per hour performed during that measurement of $\dot{V}_{\mathrm{O}_{2}}$. A one-way analysis of variance on the cost per cycle detected significant variation among the different speeds (d.f. $=3,28, F=4.073, P<0.05$ ). However, a Tukey multiple range test revealed that the only significant difference in cost per cycle occurred between 0.28 and $0.50 \mathrm{~km} \mathrm{~h}^{-1}$. The mean costs per cycle were $0.375 \mu \mathrm{lO}_{2} \mathrm{~g}^{-1}$ cycle $^{-1}(N=8$, S.E. $=0.043)$ at $0.28 \mathrm{~km} \mathrm{~h}^{-1}$ and $0.306 \mu \mathrm{I} \mathrm{O}_{2} \mathrm{~g}^{-1}$ cycle $^{-1}(N=24$, S.E. $=0.011)$ from 0.35 to $0.50 \mathrm{~km} \mathrm{~h}^{-1}$.

\section{Discussion}

\section{Comparative locomotor performance}

As in other studies of speed and endurance, the size of $C$. cerastes had a marked effect on performance. For example, a small juvenile $(S V L=25 \mathrm{~cm})$ would have a predicted burst speed and endurance time of $1.34 \mathrm{~km} \mathrm{~h}^{-1}$ and $7.8 \mathrm{~min}$, respectively, compared to those for a large adult $(S V L=50 \mathrm{~cm})$ of $2.35 \mathrm{~km} \mathrm{~h}^{-1}$ and 
Table 3. Predicted size and mass and locomotor performance (burst speed and endurance) from scaling equations of Crotalus cerastes performing sidewinding and Thamnophis sirtalis performing lateral undulation (Jayne and Bennett, 1990)

\begin{tabular}{|c|c|c|c|c|c|c|c|c|}
\hline \multirow[b]{2}{*}{$S V L$} & \multicolumn{4}{|c|}{ C. cerastes } & \multicolumn{4}{|c|}{ T. sirtalis } \\
\hline & $\begin{array}{c}T L \\
(\mathrm{~cm})\end{array}$ & $\begin{array}{c}\text { Mass } \\
(\mathrm{g})\end{array}$ & $\begin{array}{l}\text { Burst } \bar{V}_{\mathrm{x}} \\
\left(\mathrm{km} \mathrm{h}^{-1}\right)\end{array}$ & $\underset{(\mathrm{min})}{E}$ & $\begin{array}{c}T L \\
(\mathrm{~cm})\end{array}$ & $\begin{array}{c}\text { Mass } \\
\text { (g) }\end{array}$ & $\begin{array}{l}\text { Burst } \bar{V}_{\mathrm{x}} \\
\left(\mathrm{km} \mathrm{h}^{-1}\right)\end{array}$ & $\underset{(\mathrm{min})}{E}$ \\
\hline 25 & 26.8 & 14.1 & 1.34 & 7.8 & 33.2 & 5.5 & 2.18 & 5.7 \\
\hline 30 & 32.3 & 23.4 & 1.55 & 13.1 & 39.9 & 9.5 & 2.64 & 8.6 \\
\hline 35 & 37.7 & 35.8 & 1.76 & 20.3 & 46.5 & 14.9 & 2.97 & 12.2 \\
\hline 40 & 43.1 & 51.8 & 1.96 & 29.8 & 53.2 & 22.0 & 3.19 & 16.6 \\
\hline 45 & 48.5 & 71.7 & 2.16 & 41.6 & 59.9 & 31.0 & 3.30 & 21.7 \\
\hline 50 & 53.9 & 95.9 & 2.35 & 56.2 & 66.7 & 42.2 & 3.34 & 27.6 \\
\hline
\end{tabular}

See list of abbreviations for definitions of variables.

$56.2 \mathrm{~min}$ (Table 3). Jayne and Bennett (1990) used a similar protocol $\left(T=30^{\circ} \mathrm{C}\right)$ to test the performance of Thamnophis sirtalis using lateral undulation. Hence, these data are the most useful for comparisons with varying sizes of $C$. cerastes. Table 3 summarizes values of size and locomotor performance predicted for a given $S V L$ of these two species. Compared to C. cerastes, $T$. sirtalis with equal $S V L$ are less than half the mass and possess longer tails (Table 3 ). The burst speed of $T$. sirtalis is greater than that of $C$. cerastes with the smaller individuals having the most divergent values. The endurance of $T$. sirtalis is less than that of $C$. cerastes with the larger individuals having the most divergent values.

Similar to this interspecific comparison of burst speed between lateral undulation and sidewinding, Jayne (1986) found that the burst speed of sidewinding by Nerodia fasciata was less than that of terrestrial and aquatic lateral undulation performed by the same species. These measurements of speed during snake locomotion suggest that sidewinding is not an extraordinarily rapid mode of locomotion. However, it is apparent from comparative kinematic studies that snakes can move using sidewinding on surfaces where lateral undulation is extremely difficult (Gray, 1946; Gans, 1974; Jayne, 1986).

Jayne and Bennett (1990) calculated the residual of mass predicted from $S V L$ for $T$. sirtalis, and they found that this quantity, similar to other indices (Van Berkum et al. 1989) of overall condition, showed a significant quadratic relationship with locomotor performance. In other words, $T$. sirtalis that were too thin or heavy, based upon their $S V L$, showed a decrement in size-corrected (residual) burst speed and endurance. For our sample of $C$. cerastes there was no significant linear or quadratic effect of mass residual upon either burst speed residual or endurance residual. Furthermore, burst speed and endurance residuals were not significantly correlated for $C$. cerastes $(r=0.290, P=0.066)$, whereas these two quantities were significantly correlated for $T$. sirtalis, though only weakly $(r=0.263)$ (Jayne and Bennett, 1990). 
To facilitate comparisons with the study of Walton et al. (1990) on the locomotion of the snake Coluber constrictor, we selected $C$. cerastes of similar mass, and we performed all experiments at an identical temperature $\left(30^{\circ} \mathrm{C}\right)$. Comparing the size measurements of the sample of $C$. constrictor of Walton et al. $(N=7$, mean $S V L=71 \mathrm{~cm}$, mean $T L=95 \mathrm{~cm}$, mean mass $=103 \mathrm{~g})$ shows that the $C$. cerastes $(N=8$, mean $S V L=51.0 \mathrm{~cm}$, mean $T L=55.1 \mathrm{~cm}$, mean mass $=110 \mathrm{~g})$ used for energetic measurements were relatively stouter animals with shorter tails. The mean burst speed $\left(\bar{V}_{\mathrm{x}}\right)$ of these $C$. constrictor $\left(N=5, \bar{V}_{\mathrm{x}}=5.50 \mathrm{~km} \mathrm{~h}^{-1}\right)$ is more than twice that of these adult $C$. cerastes $\left(N=8, \bar{V}_{\mathrm{x}}=2.35 \mathrm{~km} \mathrm{~h}^{-1}\right)$, a highly significant difference (two-tailed $t=7.80, P<0.001$ ). Interestingly, the mean endurance times $(E)$ at $0.60 \mathrm{~km} \mathrm{~h}^{-1}$ of these $C$. constrictor $(N=6, \bar{E}=33 \mathrm{~min})$ and C. cerastes (Fig. $4, N=6, \bar{E}=73 \mathrm{~min}$ ) did not differ significantly $(t=1.550)$, primarily because of the large variance associated with these measurements in both species.

\section{Energetics}

The net cost of transport ( NCT, in $\mathrm{ml} \mathrm{O}_{2} \mathrm{~g}^{-1} \mathrm{~km}^{-1}$ ) is widely used to compare the energetic cost of aerobically sustainable locomotion among different species as well as among different modes of locomotion (Schmidt-Nielsen, 1972). A twotailed $t$-test (d.f. $=53, t=2.923, P<0.01$ ) reveals that the $N C T$ of $0.408 \mathrm{ml} \mathrm{O}_{2}$ $\mathrm{g}^{-1} \mathrm{~km}^{-1}$ for $C$. cerastes sidewinding is significantly less than the NCT of $1.15 \mathrm{ml} \mathrm{O}_{2} \mathrm{~g}^{-1} \mathrm{~km}^{-1}$ for $C$. constrictor performing terrestrial lateral undulation (Walton et al. 1990). The NCT of $8.49 \mathrm{ml} \mathrm{O}_{2} \mathrm{~g}^{-1} \mathrm{~km}^{-1}$ for C. constrictor performing concertina locomotion in $10-\mathrm{cm}$ wide tunnels is significantly greater than that for both lateral undulation (Walton et al. 1990) and sidewinding. Several studies of limbed locomotion have documented that NCT scales negatively with increasing mass (Taylor et al. 1982; Full, 1989). The scaling equation for the NCT of limbed lizards (John-Alder et al. 1986; Fig. 5) predicts a value of $1.14 \mathrm{ml} \mathrm{O}_{2} \mathrm{~g}^{-1} \mathrm{~km}^{-1}$ for a $103-\mathrm{g}$ individual, and this value is indistinguishable from the NCT of lateral undulation by Coluber but intermediate to the NCTs for concertina motion by Coluber and sidewinding by Crotalus. As emphasized in Fig. 5, the more than 20fold variation in NCT found among different locomotor modes within snakes of similar mass exceeds the amount of variation in $N C T$ reported for lizards over three orders of magnitude of mass. Hence, different modes of limbless locomotion are of primary importance in determining the energetic cost of movement.

Previous studies (Walton et al. 1990; Jayne and Davis, 1991) have suggested that some of the factors contributing to the high NCT of snake concertina locomotion relative to lateral undulation are the greater frequency of movements, smaller distance travelled per cycle of movement, and sliding plus static frictional resistance. Despite the fact that $C$. constrictor travelled less distance per cycle during concertina locomotion compared to lateral undulation, the cost per cycle of movement was significantly higher during concertina locomotion (Walton et al. 1990).

The spacing of projections from the locomotor surface affects the frequency and 


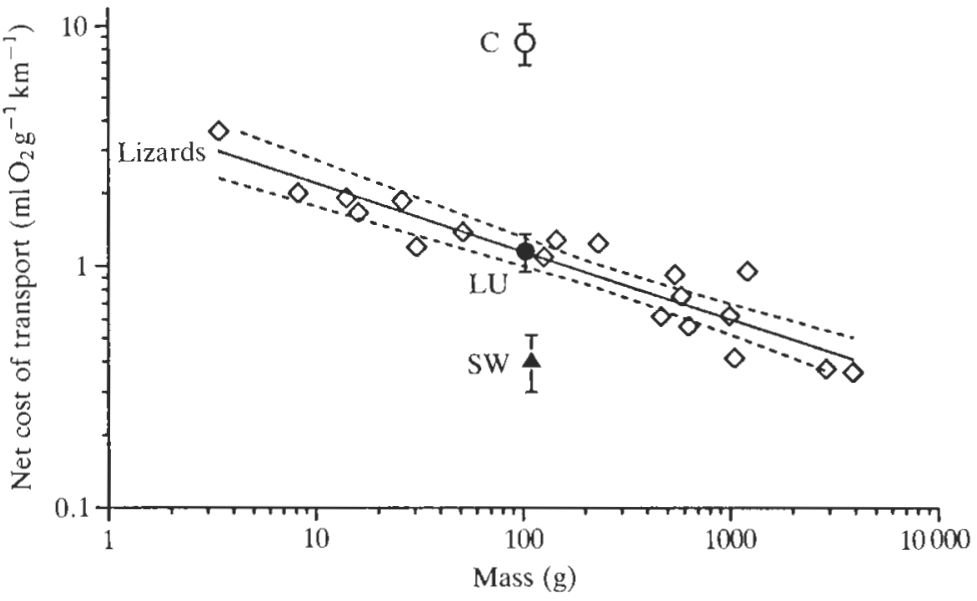

Fig. 5. Log-log plot of net cost of transport (NCT) for lizards and snakes ( \pm 1 s.E.). Sidewinding by Crotalus cerastes (this study) is designated SW and lateral undulation (LU) and concertina locomotion (C) were performed by Coluber constrictor (Walton et al. 1990). The diamonds represent species of limbed lizards (John-Alder et al. 1986). The regression ( $\pm 95 \%$ confidence limits) of $N C T$ with mass is shown for the lizard data.

amplitude of lateral undulatory movements of snakes (Jayne, 1986) but, in our studies, the two groups of snakes used to calculate $N C T$ of sidewinding and lateral undulation had similar frequencies of movement. For example, at $0.50 \mathrm{~km} \mathrm{~h}^{-1}$, C. cerastes $(N=6$, Fig. $3 \mathrm{~B})$ performed sidewinding and $C$. constrictor $(N=5$, Walton et al. 1990) performed lateral undulation with mean frequencies of 26.8 and $27.3 \mathrm{~min}^{-1}$, respectively, and these values are not significantly different $(t=0.319)$. These matching frequencies of movement at identical forward speeds indicate that the mean distance travelled per cycle must also be equal. Thus, the lower NCT of sidewinding compared to lateral undulation cannot be attributed to differences in the modulation of the frequency and amplitude of movements.

The cost per cycle of movement for aerobically sustainable speeds of sidewinding $(N=32$, Fig, 4B) is significantly lower (Mann-Whitney $U=676, P<0.001)$ than that of terrestrial lateral undulation ( $N=23$, Fig. $2 \mathrm{~B}$ in Walton et al. 1990). A similar conclusion is reached when the comparison is restricted to one speed in common to both experiments. At $0.50 \mathrm{~km} \mathrm{~h}^{-1}$, there was a significantly lower $(t=4.479, P<0.01)$ cost per cycle for sidewinding $\left(N=8\right.$, mean $=0.28 \mu \mathrm{lO}_{2} \mathrm{~g}^{-1}$ cycle $\left.^{-1}\right)$, which was about half that of lateral undulation $\left(N=5\right.$, mean $=0.52 \mu \mathrm{l} \mathrm{O}_{2}$ $\mathrm{g}^{-1}$ cycle $\left.^{-1}\right)$. Thus, to explain the different $N C T \mathrm{~s}$ of lateral undulation and sidewinding it is helpful to examine factors that could affect the cost per cycle of movement.

Snakes performing terrestrial lateral undulation propagate waves of bending posteriorly such that they push laterally and posteriorly against irregularities in the locomotor surface (Gray, 1946; Gans, 1974). The resulting reactive forces are 
directed anterio-medially and sum to a net forward reactive force (Gray and Lissman, 1950). All points on the body of the snake are propelled with a constant speed following a more or less sinusoidal path (Jayne, 1986). Hence, a laterally undulating snake must exert forces sufficient to (1) bend its body laterally, (2) push its sides against vertical surfaces, (3) overcome lateral sliding frictional resistance, and (4) overcome ventral sliding frictional resistance $(=$ snake weight $\times$ coefficient of friction).

During sidewinding, snakes must exert forces sufficient to bend the body laterally as it is pushed away from one region of static contact and pulled towards a more anterior region of static contact with the ground (Fig. 1). Sidewinders must also lift the body between regions of contact with the substratum. This movement is accomplished by dorsiflexion of the vertebral column. Hence, lateral flexion is common to both sidewinding and terrestrial lateral undulation. Both locomotor modes use the longissimus dorsi and iliocostalis muscles as the primary lateral flexors and these epaxial muscles are activated in an alternating unilateral fashion with a posterior propagation of muscle activity such that the contractile tissue is active as it shortens (Jayne, 1988a,b). These similarities in lateral bending suggest that similar amounts of work may be done for this portion of movement in the two locomotor modes.

The pattern of muscle activity that is unique to sidewinding is the bilateral activation of the most medial epaxial muscles in order to dorsiflex and lift the snake's body away from the ground (Jayne, 1988a), and specialized sidewinding species have fewer vertebrae spanned by these muscles than generalized species (Jayne, 1982). Based on the low energetic cost of sidewinding, this lifting of the body appears to be energetically much more economical than the combined work that must be done during lateral undulation to overcome the ventral and lateral sliding frictional forces.

In lateral undulation, the proportion of total work done to overcome external frictional forces remains unclear. It is also unclear if sidewinding is energetically more costly in snake species lacking the specialized anatomical features common to proficient sidewinders. Compared to snake species that largely use other modes, sidewinding specialists have fewer vertebrae (Jayne, 1982), possess shorter segments of epaxial musculature (Jayne, 1982) and are small (TL less than $90 \mathrm{~cm}$ ), moderately stout-bodied with relatively short tails (Broadley, 1962; Gans and Mendelssohn, 1972; Klauber, 1972; Moore, 1980). Jayne (1986) noted that the relatively longer tail of Nerodia fasciata was ineffective during sidewinding.

The mean pre-exercise rate of oxygen consumption $\left(0.108 \mathrm{mlO}_{2} \mathrm{~g}^{-1} \mathrm{~h}^{-1}\right)$ is similar to the predicted resting metabolic rate of squamate reptiles of equivalent mass $(110 \mathrm{~g})$ at $30^{\circ} \mathrm{C}\left(0.0968 \mathrm{ml} \mathrm{O}_{2} \mathrm{~g}^{-1} \mathrm{~h}^{-1}\right.$, Andrews and Pough, 1985). Maximal oxygen consumption during the locomotion of $C$. cerastes in our study was about half that observed for C. constrictor during lateral undulation (Walton et al. 1990). However, the lower energetic cost of sidewinding enabled $C$. cerastes to have a maximal sustainable aerobic speed (about $0.6 \mathrm{~km} \mathrm{~h}^{-1}$ ) equal to that of $C$. constrictor performing lateral undulation (Walton et al. 1990). Maximal aerobic speeds are 
$28 \%$ and $10 \%$ of burst speed in Crotalus and Coluber, respectively. Our findings, and those of Walton et al. (1990), agree closely with those of Ruben (1976), who used different methods to obtain $\dot{V}_{\mathrm{O}_{2} \max }$. Ruben (1976) found that Coluber had $\dot{V}_{\mathrm{O}_{2} \max }$ about twice and maximal whole-body levels of lactate about 1.5 times those of the rattlesnake Crotalus viridis. Interestingly, by using a different locomotor behaviour from Coluber, C. cerastes was able to obtain similar endurance and maximal aerobic speed as Coluber, which had much greater aerobic scope. Explaining the more than twofold difference in burst speed between Coluber and C. cerastes remains an intriguing problem. It is not obvious whether it is differing mechanics, morphology or physiological capacity that explains the different burst speed of $C$. cerastes sidewinding compared to that of $C$. constrictor laterally undulating.

\section{List of abbreviations}

$D \quad$ Distance travelled per cycle of movement $(\mathrm{cm})$

E Endurance time at a constant tread speed ( $\mathrm{min})$

$f \quad$ Frequency of movement $\left(\right.$ cycles s $^{-1}$ )

$M \quad$ Body mass (g)

NCT Net cost of transport $\left(\mathrm{ml} \mathrm{O}_{2} \mathrm{~g}^{-1} \mathrm{~h}^{-1}\right)$

SVL Snout-vent length of snake $(\mathrm{cm})$

$T L \quad$ Total length of snake $(\mathrm{cm})$

$\bar{V}_{\mathrm{x}} \quad$ Mean forward velocity $\left(\mathrm{km} \mathrm{h}^{-1}\right)$

Financial support was provided by University of California Natural Reserve System and University of California, Los Angeles, to S.M.S., and by National Science Foundation grants BNS 8919497 to B.C.J. and DCB 88-12028 and BSR 89-18054 to A.F.B. We wish to thank C. Wallace and J. Davis for technical assistance. We are grateful to the University of California's Granite Mountain Reserve for lodging while collecting snakes.

\section{References}

Andrews, R. M. And Pough, F. H. (1985). Metabolism of squamate reptiles: allometric and ecological relationships. Physiol. Zool. 58, 214-231.

Arnold, S. J. And BennetT, A. F. (1984). Behavioural variation in natural populations. III. Antipredator displays in the garter snake Thamnophis radix. Anim. Behav. 32, 1108-1118.

BennetT, A. F. (1985). Energetics and locomotion. In Functional Vertebrate Morphology (ed. M. Hildebrand, D. M. Bramble, K. F. Liem and D. B. Wake), pp. 173-184. Cambridge: Belknap Press of Harvard University Press.

Broadley, D. G. (1962). Fitz,Simons' Snakes of Southern Africa. Johannesburg: Delta Books Ltd.

Cadle, J. E. (1987). Geographic distribution: problems in phylogeny and zoogeography. In Snakes: Ecology and Evolutionary Biology (ed. R. A. Seigel, J. T. Collins and S. S. Novak), pp. 77-105. New York: Macmillan Publishing Company.

Duellman, W. E. (1979). The numbers of amphibians and reptiles. Herp. Rev. 10, 83-84.

EDwards, J. L. (1985). Terrestrial locomotion without appendages. In Functional Vertebrate 
Morphology (ed. M. Hildebrand, D. M. Bramble, K. F. Liem and D. B. Wake), pp. 159-172. Cambridge: Belknap Press of Harvard University Press.

FIтcH, H. S. (1987). Collecting and life-history techniques. In Snakes: Ecology and Evolutionary Biology (ed. R. A. Seigel, J. T. Collins and S. S. Novak), pp. 143-164. New York: Macmillan Publishing Company.

Full, R. J. (1989). Mechanics and energetics of terrestrial locomotion: birds to polypeds. In Energy Transformations in Cells and Organisms (ed. W. Wieser and E. Gnaiger), pp. 175-185. New York: Georg Thieme Verlag.

Gans, C. (1974). Biomechanics: An Approach to Vertebrate Biology. Ann Arbor: University of Michigan Press.

Gans, C. And Mendelssohn, H. (1972). Sidewinding and jumping progression of vipers. In Toxins of Animal and Plant Origin (ed. A. de Vries and E. Kochva), pp. 17-38. London: Gordon and Breach.

GrAY, J. (1946). The mechanism of locomotion in snakes. J. exp. Biol. 23, 101-120.

Gray, J. and Lissman, H. W. (1950). The kinetics of locomotion of the grass snake. J. exp. Biol. 26, 354-367.

JAYNE, B. C. (1982). Comparative morphology of the semispinalis-spinalis muscle of snakes and correlations with locomotion and constriction. J. Morph. 172, 83-96.

J AYNE, B. C. (1986). Kinematics of terrestrial snake locomotion. Copeia 1986, 195-208.

JAYNE, B. C. (1988a). Muscular mechanisms of snake locomotion: An electromyographic study of lateral undulation of the Florida banded water snake (Nerodia fasciata) and the yellow rat snake (Elaphe obsoleta). J. Morph. 197, 159-181.

JAYNE, B. C. (1988b). Muscular mechanisms of snake locomotion: an electromyographic study of the sidewinding and concertina modes of Crotalus cerastes, Nerodia fasciata and Elaphe obsoleta. J. exp. Biol. 140, 1--33.

J AYNe, B. C. AND Bennett, A. F. (1990). Scaling of speed and endurance in garter snakes: a comparison of cross-sectional and longitudinal allometries. J. Zool., Lond. 220, 257-277.

JAYNE, B. C. AND DAvis, J. D. (1991). Kinematics and performance capacity for the concertina locomotion of a snake (Coluber constrictor). J. exp. Biol. 156, 539-556.

John-Alder, H. B., Garland, T. And Bennett, A. F. (1986). Locomotory capacities, oxygen consumption, and the cost of locomotion of the shingle-back lizard (Trachydosaurus rugosus). Physiol. Zool. 59, 523-531.

Klauber, L. M. (1972). Rattlesnakes: Their Habits, Life Histories, and Influence on Mankind. Berkeley: University of California Press.

Moore, G. M. (1980). Poisonous Snakes of the World. Kent, England: Castle House Publications Ltd.

Moore, R. G. (1978). Seasonal and daily activity patterns and thermoregulation in the southwestern speckled rattlesnake (Crotalus mitchelli pyrrhus) and the Colorado River sidewinder (Crotalus cerastes laterorepens). Copeia 1978, 439-442.

Mosauer, W. (1932). On the locomotion of snakes. Science 76, 583-585.

Mosauer, W. (1935). The reptiles of a sand dune area and its surroundings in the Colorado Desert, California: a study in habitat preference. Ecology 16, 13-27.

Ruben, J. A. (1976). Aerobic and anaerobic metabolism during activity in snakes. J. comp. Physiol. 109, 147-157.

SCHMIDT-NIELSEN, K. (1972). Locomotion: energy cost of swimming, flying and running. Science 177, 222-228.

Taylor, C. R., Heglund, N. C. And Maloiy, G. M. O. (1982). Energetics and mechanics of terrestrial locomotion. J. exp. Biol. 97, 1-21.

Van Berkum, F. H., Huey, R. B., Tsum, J. S. and Garland, T. (1989). Repeatability of individual differences in locomotor performance and body size during early ontogeny of the lizard Sceloporus occidentalis. Funct. Ecol. 3, 97-107.

Walton, M., Jayne, B. C. And Bennett, A. F. (1990). The energetic cost of limbless locomotion. Science 249, 524-527.

Wrthers, P. C. (1977). Measurements of $\dot{\mathrm{V}}_{\mathrm{O}_{2}}, \dot{\mathrm{V}}_{\mathrm{CO}_{2}}$, and evaporative water loss with a flow through mask. J. appl. Physiol. 42, 120-123. 